\section{ARGUMENTACIÓN Y METÁFORA EN EL DISCURSO POLÍTICO EN TORNO A LA INMIGRACIÓN ${ }^{1}$}

\author{
Gracia Piñero Piñero \\ Universidad de Las Palmas de Gran Canaria \\ gracia.pinero@ulpgc.es \\ Marina Díaz Peralta \\ Universidad de Las Palmas de Gran Canaria \\ marina.diazperalta@ulpgc.es \\ María J. García Domínguez \\ Universidad de Las Palmas de Gran Canaria \\ mariajesus.garcia@ulpgc.es
}

Cómo citar este artículo/Citation: Piñero Piñero, G.; Díaz Peralta, M. y García Domínguez, M. J. (2015). "Argumentación y metáfora en el discurso político en torno a la inmigración". Arbor, 191 (772): a224. doi: http://dx.doi.org/10.3989/ arbor.2015.772n2010

Recibido: 1 julio 2013. Aceptado: 2 diciembre 2014.

RESUMEN: La metáfora conceptual, desarrollada en el marco de la lingüística cognitiva, constituye una herramienta más al servicio de las operaciones de apoyo y refutación propias de la secuencia argumentativa $y$, por ello, permite reconocer un juego de voces polifónicas a través del cual se reflejan ideologías opuestas que representan su particular visión sobre los acontecimientos debatidos. A partir de un corpus de textos pertenecientes al hipergénero del debate social en torno a la inmigración, se analizan las metáforas conceptuales y lingüísticas que categorizan el país receptor de inmigrantes y la imagen que de estos se tiene. Mediante el estudio de esta imaginería se comprueba cómo la selección de los dominios fuente y de las estructuras conceptuales que generan propician el diálogo virtual entre ideologías opuestas, defensora y detractora del fenómeno de la inmigración, y se pone de manifiesto que, efectivamente, la metáfora desempeña una función relevante en la argumentación.

PALABRAS CLAVE: argumentación; metáfora; inmigración; ideología; debate.

\section{ARGUMENT AND METAPHOR IN POLITICAL DISCOURSE ON IMMIGRATION}

Copyright: (C) 2015 CSIC. Este es un artículo de acceso abierto distribuido bajo los términos de la licencia Creative Commons Attribution-Non Commercial (by-nc) Spain 3.0.

ABSTRACT: The conceptual metaphor, developed within the framework of cognitive linguistics, constitutes a tool for both supporting and refuting trains of argument; it therefore enables a collection of polyphonic voices to be identified, reflecting opposing ideologies and representing their particular vision of the events under debate. From a corpus of texts belonging to the "hypergenre" of the social debate concerning immigration, we analyse the conceptual and linguistic metaphors that categorize the host country and the image of immigrants. Through a study of this imagery, we demonstrate that the choice of source domains and of conceptual structures generates a virtual dialogue between opposing ideologiessupporters and detractors of the phenomenon of immigration-and show that, in effect, metaphor plays an important role in the process of argument.

KEYWORDS: argument; metaphor; immigration; ideology; debate. 


\section{INTRODUCCIÓN}

Decía Bajtín (1986) que la palabra tiene dos dimensiones, la de la persona que la emite y la de la persona a quien va dirigida, lo que le imprime un carácter dialógico. Esta afirmación se hace evidente en la secuencia argumentativa, que, por definición (Adam, 1986, 1992), tiene una naturaleza persuasiva, pues se orienta hacia el hacer creer o el hacer hacer, o ambas cosas, a uno o más receptores. Toda secuencia argumentativa, por tanto, se inscribe en una corriente polifónica, derivada precisamente del carácter polémico del tema y de las operaciones con las que se da cabida a la voz del otro para apuntalar la propia tesis o para confutar la ajena. El hablante, dice Bajtín (1986), no va a buscar las palabras al diccionario antes de hablar: el hablante va a buscar las palabras a las bocas de los demás, donde existían en otros contextos y con otras intenciones.

No cabe duda de que la metáfora puede comportarse como una herramienta eficaz al servicio de estas operaciones de apoyo y refutación argumentativas, como han puesto de manifiesto corrientes de pensamiento que se inician con la retórica clásica y que continúan con la teoría de la metáfora conceptual, surgida en el marco de la lingüística cognitiva. En este sentido, la nueva retórica, que hunde sus raíces en la tradición aristotélica al tiempo que parece apuntar ${ }^{2}$ el concepto de metáfora posteriormente alumbrado por la lingüística cognitiva, señala el importante papel que esta figura de pensamiento desempeña en la argumentación (Perelman y Olbrechts-Tyteca, 1958; Toulmin, 1958), en tanto que impone una manera de reflexionar o de situar la reflexión en un marco conceptual determinado. En esta línea, Osborn y Ehninger (1962) y Osborn (1967) acuñan el término de metáfora arquetípica para referirse a aquella imaginería especialmente generalizada en el discurso retórico, que se mantiene de generación en generación, que está motivada en la experiencia humana y que presenta un gran potencial persuasivo. Todas estas características permiten a Osborn (1967) afirmar lo siguiente:

[...] archetypal metaphors are characterized by their prominence in rethoric, their tendency to occupy important positions within speechs, and their especial significance within the most significant speechs of a society.

Ya en el contexto de las ciencias cognitivas (Lakoff y Johnson, 1980, 1999; Johnson, 1987, 1993; Lakoff, 2008; Lakoff y Turner, 1989; Turner, 1991; Sweetser, 1990; y Kövecses, 2002, 2005), se señala la metáfora, mecanismo de categorización basado en el emparejamiento de dos dominios cognitivos, como parte sustancial del significado del discurso, pues ofrece conexiones relevantes para el desarrollo de un argumento. La metáfora se entiende entonces como una fórmula de condensación del significado que permite conceptualizar realidades complejas o abstractas en términos de otras más sencillas, más concretas y, por ello, más asequibles. El resultado es un isomorfismo o "reconocimiento de un conjunto de relaciones comunes en el seno de entidades diferentes" (Millán y Narotzky, 1986, pp. 16-17) que contribuye a explicar o esclarecer una determinada esfera de la experiencia.

Autores como Pielenz (1993) y Santibáñez (2010), apoyándose en el modelo de argumentación de Toulmin (1958), asignan a la metáfora conceptual la función de respaldo, porque surgen de la experiencia corporeizada del hablante; o de garantía, es decir, de puente para legitimar el paso entre la premisa y la conclusión (Toulmin, 1958, pp. 134-143). En este sentido, Musolff (2004, pp. 32-33), a propósito del papel de la metáfora conceptual en el discurso político, explica:

[...] I propose to regard political metaphors as integral aspects of argumentative reasoning, i.e. reasoning which typically aims to prove a contested issue [...]. They must function in some way like warrants in an argument, i.e. they must appear to give a valid justification for using particular premises in order to arrive to a certain conclusión.

Con estos supuestos, nos proponemos comprobar cómo las metáforas conceptuales, junto con sus instanciaciones lingüísticas, se convierten en un mecanismo útil en las operaciones de apoyo y refutación argumental en debates de prensa acerca de la inmigración y, por tanto, en un instrumento más de la polifonía sustancial al texto argumentativo, en el que cristaliza este hipergénero que, según Bañón (2002, 2008), es el debate social, centrado en nuestro caso en la política migratoria.

\section{DESCRIPCIÓN DEL CORPUS}

De acuerdo con nuestro propósito de analizar la metáfora como mecanismo de argumentación en el discurso de la prensa en torno a la inmigración, hemos seleccionado un corpus procedente de una geografía, el condado estadounidense de San Diego, donde se encuentra el cruce fronterizo de mayor flujo del mundo y donde, consecuentemente, reside una nutrida comunidad de inmigrantes de origen mexicano. A ella precisamente se dirigen periódicos en lengua española, en los que este debate se convierte en protagonista habitual de la actualidad informativa. Nuestro corpus está extraído de un segmento cronológico (entre los 
meses de septiembre y diciembre de 2011) en el que se agudiza la crisis social generada por el problema migratorio, en tanto que la promesa efectuada por Obama durante la campaña electoral que lo llevó a ocupar por vez primera la presidencia no se ha llevado a efecto y su mandato está a punto de expirar. $Y$ como dice Osborn (1967), cuando la sociedad está en crisis, el hablante vuelve su mirada a lo simbólico, a lo arquetípico, a lo que representa la esencia inmutable de la identidad humana.

Particularmente, hemos seleccionado tres publicaciones semanales, Frontera San Diego, El Latino y La Prensa de San Diego, de las que hemos extraído un corpus de textos relacionados con el fenómeno migratorio integrado específicamente por el total de los 119 artículos de opinión sobre el tema de la inmigración aparecidos en este segmento cronológico; se trata, por tanto, de un corpus construido sobre un muestreo opinático o intencional, pues se ha elaborado mediante material procedente de un grupo de publicaciones representativo.

En tales artículos, por definición, el autor desarrolla una argumentación con la que pretende obtener la adhesión del receptor. Al servicio de esta función persuasiva se disponen mecanismos diversos, entre los cuales desempeña un papel esencial la metáfora conceptual (Semino, 2008, pp. 85-86), objeto de estudio de la retórica cognitiva, que se ocupa de "how figurative conceptualization bears upon pragmatic persuasion" (Hamilton, 2003, p. 359). Pondremos de manifiesto con nuestro estudio que tales analogías conforman un cuerpo conceptual coherente que revela la ideología del grupo social que las emplea, entendida como conjunto de creencias y valores que proporcionan patrones para actuar y desenvolverse en una sociedad (Fairclough, 2003, p. 9).

\section{ANÁLISIS}

Hemos de señalar que los estudios centrados en el discurso político sobre la inmigración nos han ofrecido preferentemente el retrato efectuado por la ideología hostil hacia el extranjero (Santa Ana, 2002, 2003; Flores, 2003; Cisneros, 2008; Semino, 2008; Chilton, 2004; Musolff, 2011), que, entre otras representaciones, conceptualiza al país receptor como un recipiente de capacidad limitada que soporta un exceso de presión, ejercida por los inmigrantes.

Como comprobaremos a través del análisis, esta misma conceptualización del país receptor va a ser también utilizada por voces que se identifican social y emocionalmente con el inmigrante, con lo que, tal y como hemos advertido, se comporta como una herramienta discursiva que, con la aplicación de los procesos cognitivos pertinentes, permite reconocer el anclaje ideológico de los participantes en el debate político y social y, consecuentemente, la polifonía, el dialogismo inherente a la secuencia argumentativa.

De igual modo, estudiaremos la conceptualización metafórica del inmigrante con el fin de comprobar cómo los autores de nuestros textos citan en su discurso comprometido (Bañón, 2008, p. 25) tanto su ideología como la de su antagonista, con el propósito de distanciarse de ella, de cuestionarla, de negarla, porque introduce un punto de vista opuesto a su ideario, en tanto que, como discurso discriminatorio (Bañón, 2008, p. 25), arrastra una distorsión de la imagen del inmigrante, convertido a los ojos de la audiencia en una realidad nociva para el país. A través de estas metáforas descubrimos el modo en que unos y otros, haciendo uso de narrativas ${ }^{3}$ opuestas, estructuran un componente de la experiencia para orientar al receptor en la manera en que debe comprenderlo.

Con estos presupuestos, el análisis se ha desarrollado de acuerdo con la siguiente metodología. En primer lugar, hemos buscado instanciaciones lingüísticas en las que se materializan las metáforas conceptuales relacionadas con el fenómeno de la inmigración más recurrentes en nuestro corpus; seguidamente, hemos observado los procesos cognitivos que contribuyen a construir la identidad discursiva de los inmigrantes y del país que los acoge según los intereses y el sesgo ideológico de los autores de nuestros textos.

\subsection{Conceptualización metafórica del país receptor de inmigrantes: el esquema de imagen RECIPIENTE}

La lingüística cognitiva ha puesto de manifiesto desde la obra seminal de Lakoff y Johnson (1980) la trascendencia que posee la experiencia, o interacción de nuestros cuerpos con el entorno, como fundamento de cualquier representación conceptual, incluida la metafórica. En este sentido, la noción de esquema de imagen es básica en la literatura cognitiva, pues, como afirma Johnson (1987, p. 13), es un patrón dinámico y recurrente de la cognición humana, que emerge de la interacción social y corporal que tiene lugar dentro de un amplio conjunto de presuposiciones culturales y que proporciona una estructura coherente y significativa para conceptualizar aspectos más abstractos de la realidad. Estos modelos cognitivos poseen un gran potencial estructurador y por ello pueden proporcionar el dominio fuente de las metáforas imagoesquemáticas, que se prestan a razonamientos com- 
plejos (Ruiz de Mendoza Ibáñez y Otal, 2002; Ruiz de Mendoza Ibáñez y Pérez Hernández, 2011).

Uno de estos esquemas de imagen, dependiente del nodo dominante REGIón DELIMITADA (Johnson, 1987; Peña Cervel, 2012), es el de RECIPIENTE, descrito por Lakoff y Johnson (1980, p. 29) del siguiente modo:

We are physical beings, bounded and set off from the rest of the world by the surface of our skins, and we experience the rest of the world as outside us. Each of us is a container, with a bounding surface and an in-out orientation.We project our own in-out orientation onto other physical objects that are bounded by surfaces. Thus we also view them as containers with an inside and an outside.

Este esquema, compuesto por los elementos estructurales interior, exterior y límite, proporciona la estructura organizativa preconceptual de la metáfora EL PAÍS RECEPTOR DE INMIGRANTES ES UN RECIPIENTE, en la que, con su gran capacidad explicativa, se constituye en dominio origen para crear "a contrast between what is inside and what is outside" (Semino, 2008, p. 95); este esquema se articula en torno a la idea de que los límites impiden que lo que está fuera perjudique a las entidades que se encuentran en el interior del contenedor (Johnson, 1987; Lakoff, 1989).

Se trata, como ya hemos señalado, de un esquema de imagen frecuente en el discurso político xenófobo (entre otros, Semino, 2008, p. 95; Charteris-Black, 2009) para establecer representaciones negativas de grupos minoritarios, como los inmigrantes, y para categorizar situaciones de conflicto entre grupos sociales, uno de los cuales, el que está dentro, se siente amenazado por la presión ejercida por el otro, el que está fuera, de tal manera que la amenaza se construye metafóricamente como la posibilidad de que ese otro pueda acceder al interior del contenedor y causar problemas ${ }^{4}$. Como afirma Douglas (1984, p. 5), exacerbando las diferencias entre lo que está dentro y lo que está fuera, se crea una apariencia de orden.

Este modelo imago-esquemático del recipiente (EL PAÍS RECEPTOR DE INMIGRANTES ES UN RECIPIENTE) genera, en nuestro caso, un haz de correspondencias $^{5}$ según las cuales las paredes del contenedor se proyectan en el dominio meta sobre los límites territoriales del país; los objetos que contiene el recipiente se proyectan sobre los habitantes; $y$, finalmente, la categoría que indica el mecanismo de acceso al recipiente se empareja en el dominio meta con el concepto de frontera. Analizaremos esta imaginería y comprobaremos que, a través de procesos cognitivos como la distribución de roles semánticos generados por este modelo idealizado, se descubre un reparto de funciones que pone al descubierto, por un lado, el punto de vista del inmigrante, quien percibe el riesgo de ser expulsado del contenedor; y, por otro lado, el de los ciudadanos del país anfitrión, que sienten el riesgo de que los otros accedan a él. Es decir, observaremos la misma metáfora al servicio de planteamientos ideológicos contrapuestos, lo que corrobora el aserto de Le Guern (1973), quien explicaba que las metáforas argumentativas requieren un alto grado de difusión y de aceptación para que sean admitidas por todos los potenciales destinatarios del discurso.

En nuestro corpus, cuyos autores reivindican la figura del inmigrante, el rol de objeto de la amenaza se asigna a este, y no al país receptor y a sus ciudadanos; la amenaza se corresponde con la expulsión del contenedor, con la deportación, y no con el ingreso en el contenedor; $y$, finalmente, el rol de agente de la amenaza se adjudica al país de acogida, que combate el fenómeno de la inmigración, y no a los inmigrantes, como sucede en el discurso político contrario a este colectivo. En definitiva, un reparto de funciones en el que el inmigrante resulta conceptualizado como el objeto del daño que otros le causan, como la víctima amenazada por la expulsión del contenedor, y no, según lo presenta el discurso xenófobo, como agente del daño que otros sufren.

La representación de EEUU como un recipiente cerrado se materializa lingüísticamente en nuestros textos con la aparición de términos como entrar o ingresar, que representan el paso del exterior al interior del contenedor. Se trata de expresiones lingüísticas que reproducen el patrón metafórico convencional dentro / fuera y que, como vemos en la muestra siguiente, no solo puede instanciarse a través de preposiciones (Lakoff y Turner, 1989, pp. 97-99), sino también de verbos, que incorporan la misma relación espacial de estar en el interior o en el exterior de un espacio cercado:

Desde luego que las casi 2 mil millas de frontera entre ambos países no tienen el mismo tipo de vigilancia, pero las cifras nos indican que el paso de indocumentados hacia el norte se ha reducido dramáticamente. En el año 2000 se arrestó a más de 1.6 millones de inmigrantes tratando de entrar; esos números cayeron a solo 400 mil en el año 2010. Además, las deportaciones se han incrementado. Barack Obama ha deportado a más de 1.2 millones de indocumentados, y los efectos son notables (FSD, 01-12-2011) ${ }^{6}$. 
La nueva modalidad clausura los casos en los que los inmigrantes no tengan antecedentes penales, hayan entrado hace tiempo a Estados Unidos y no hayan quebrantado ninguna otra ley migratoria (LPSD, 09-12-2011).

Es evidente que la medida busca beneficiar a los inmigrantes honestos que buscan hacerse una vida de este lado de la frontera. Una frontera, al parecer, cada vez un poco menos congestionada. De acuerdo con cifras del Washington Post durante el año fiscal 2011 que culminó en septiembre la Patrulla Fronteriza arrestó apenas a 327,577 personas ingresando ilegalmente por la frontera con México (LPSD, 09-12-2011).

En estos tres fragmentos, los lexemas verbales entrar e ingresar ponen en funcionamiento a través de su intransitividad el esquema de imagen FUERZA, que conceptualiza al inmigrante como una entidad en movimiento capaz de alcanzar un destino. Se trata de vocablos que verbalizan lo que Mandler (1992, p. 593) denomina self-instigated motion para describir la experiencia de un objeto que se mueve por sí mismo sin que nada lo empuje. Algo muy diferente sucederá en posteriores muestras, en las que el empleo de vocablos como sacar, expulsar y expulsión añade a la idea de fuerza la noción de arrollamiento.

Efectivamente, el binomio dentro / fuera se instancia también, como se comprueba en los extractos que presentamos seguidamente, mediante el término sacar, 'poner algo fuera del lugar donde estaba encerrado o contenido' (DRAE, 2001), que se proyecta en el dominio meta sobre el concepto deportar; es decir, el inmigrante sacado del contenedor es el inmigrante deportado. Frente a entrar e ingresar, la transitividad del verbo sacar convierte sistemáticamente al inmigrante en objeto que experimenta la acción ejecutada por esos otros que aplican las leyes de control migratorio; esta propiedad gramatical verbaliza la idea de caused-motion (Mandler, 1992, p. 593), al señalar un objeto movido o empujado por otro:

Lizbeth indicó que "si es mi turno de que me saquen, pues es mi turno". "Trabajo todo el día limpiando tiendas con mi mamá. Soy la que maneja. Dejo a mi niña con mi tía y sólo pensar que me arresten y que no pueda volver a verla me rompe el corazón. Esta ley está separando a muchas familias (EL, 21-10-2011).

"Tenemos casa, tenemos trabajo, seguro médico y pagamos impuestos", indicó. Si el esposo se va, "mi niño tendría que recibir Medicaid, yo seré elegible para estampillas de alimentos, entonces yo me convertiré en una carga para el estado porque ellos deportaron a mi esposo... No piensan que están separando familias, piensan que toda la familia es indocumentada y los están sacando", afirmó (EL, 04-11-2011).
Desde 2003 hasta la terminación del año fiscal de 2011, en septiembre pasado, las autoridades de inmigración sacaron del país a más de dos millones y medio de indocumentados (LPSD, 11-11-2011).

Esta idea de abandono involuntario del contenedor, fruto de la aplicación de una ley, se intensifica en la muestra siguiente con la presencia de la locución adverbial por la fuerza:

El 22 de noviembre, en un debate en la CNN, Gingrich fue más específico. "Si tú has estado aquí por 25 años, tienes tres hijos y dos nietos, has pagado impuestos, cumples las leyes y vas a misa", explicó el exlíder del Congreso, "no creo que te vamos a separar de tu familia, por la fuerza, y sacarte de aqui" (FSD, 01-12-2011).

Otras veces, la deportación cristaliza en los vocablos expulsar 'arrojar lanzar algo, hacer salir algo del organismo, echar a una persona de un lugar' (DRAE, 2001) o expulsión, que también reproducen el esquema CAUSED-MOTION. De este modo, la idea de que el inmigrante no es agente sino paciente del proceso verbal, expresada antes mediante procedimientos como la transitividad del verbo sacar o locuciones adverbiales del tipo de por la fuerza, se explicita ahora a través de mecanismos léxico-semánticos que añaden un rasgo de resistencia, de manera que el inmigrante, de nuevo en contra de su voluntad, es arrojado del contenedor.

Por tanto, todas estas metáforas lingüísticas, mediante el empleo de los vocablos sacar, expulsión o expulsar, activan, además del esquema de imagen FUERZA, el esquema subsidiario coMpuLsıón (Johnson, 1987; Peña Cervel, 1999); el inmigrante es la entidad pasiva obligada a salir del contenedor por una fuerza arrolladora, con suficiente poder para desplazarla, esto es, las leyes de control migratorio y las autoridades que las aplican:

Esto es lo que muchos llaman la tercera opción. No es la primera opción -favorecida por el presidente Barack Obama y muchos Demócratas- que legalizaría a la mayoría de los indocumentados y les daría la ciudadanía norteamericana. Tampoco es la segunda opción, de los Republicanos más radicales, que propone expulsar del país a todos los extranjeros sin documentos de residencia (FSD, 01-12-2011).

Mi tesis central sostenía que el gobierno local pretendía expulsar de sus confines jurídicos a la gente latina y a sus familiares cercanos, muchos de ellos ciudadanos estadounidenses, a través de ordenanzas municipales radicales y racistas (LPSD, 14-10-2011).

El proyecto, que contemplaba la expulsión del país de todos los indocumentados entre 2003 y 2012, no cumplirá la meta para la fecha fijada, pero si sentó las 
bases para confeccionar la pesadilla que viven los inmigrantes que carecen de papeles (LPSD, 11-11-2011).

Partiendo del plan se dio la espiral de expulsiones que fue subiendo en cada año fiscal: 2003, 155,874; 2004, 173,777; 2005, 179,165; 2006, 206,177; 2007, 288,663; 2008, 349,041; 2009, 387,790; 2010, 392,862; y 2011, 396,906 (LPSD, 11-11-2011).

Recientemente me dijo que el mandatario ha estado "atado de manos", refiriéndose al fracaso de su promesa de alcanzar una reforma migratoria integral que legalice a los indocumentados y alivie tanto dolor en los hogares de los inmigrantes, con la expulsión de un millón de sus congéneres (EL, 09-09-2011).

El modelo idealizado RECIPIENTE se concreta también en un concepto, is/a, que comparte la definición de espacio circunscrito. Así, en el fragmento extractado a continuación, el autor utiliza este vocablo para dar cabida en su texto al deseo del país anfitrión -y de las fuerzas que despliega para lograr que se haga realidad-de mantenerse a salvo de los inmigrantes; y lo hace mediante la personificación de la nación en términos de motivaciones y actividades humanas (Lakoff y Jonson, 1980, p. 33); en los siguientes ejemplos, el esquema del recipiente, instanciado aquí en un lexema que contiene sus dos parámetros definitorios esto es, cercamiento y separación (Peña Cervel, 2012, p. 89) - se emplea para indicar el deseo de EEUU de aislarse de los que están fuera:

El país que quería ser una isla (Título de artículo) (FSD, 20-10-2011).

Hay días en que Estados Unidos quisiera ser una isla y cuando eso ocurre los inmigrantes que ya viven en este pedazo de tierra son los primeros en pagar las consecuencias (FSD, 20-10-2011).

Hay veces en que Estados Unidos quisiera ser una isla. Más que estar rodeada de agua, la característica principal de una isla es estar aislada. Aislada de peligros y amenazas, de contagios, de contactos indeseables, de extranjeros (FSD, 20-10-2011).

En las primeras secuencias extractadas, el esquema del recipiente se utilizaba para poner al descubierto el punto de vista de quienes se sienten amenazados por la expulsión; en estos fragmentos, el vocablo isla introduce la voz de los otros, cuestionada aquí por la degradación a la que somete al inmigrante, al extranjero, retratado, mediante una suma de conceptos (peligros, amenazas, contagios, contactos indeseables), como esa realidad dañina y peligrosa de la que el país quiere guardarse.

\subsubsection{Conceptualización metafórica de la frontera: el mecanismo de cierre del recipiente}

En el epígrafe anterior hemos anunciado que la estructura conceptual generada por la imagen del recipiente contiene una subcategoría, el mecanismo de cierre, que se proyecta en el dominio meta sobre la frontera (LA FRONTERA ES EL MECANISMO DE CIERRE DEL RECIPIENTE). Esta subcategoría se materializa en nuestros textos en diversas submetáforas, en la primera de las cuales se concreta en el concepto de puerta (LA FRONTERA ES UNA PUERTA), dispositivo que se abre y se cierra para permitir o impedir el paso al inmigrante:

Katie, la estadounidense, opinó que la ley es racista. Si los inmigrantes están trabajando, "déjalos trabajar y cuidar a su familia, no les cierren la puerta" (EL, 21-10-2011).

Estados Unidos, a lo largo de su historia, ha sido sumamente generoso con los inmigrantes. Desde luego, han existido momentos en que esta nación ha rechazado y discriminado a extranjeros de Alemania, China, Japón, Irlanda y América Latina, entre muchos otros. Pero, al final de cuentas, siempre rectifica y vuelve a abrir sus puertas a los inmigrantes (FSD, 17-11-2011).

La elección del vocablo puerta pone en evidencia, a nuestro juicio, la valoración positiva que hace el inmigrante del país anfitrión, pues, aunque descontextualizado tiene un valor neutro, en nuestros textos este término adquiere una axiología positiva; esta valoración positiva se constata al compararlo con el modo en que los que se sienten amenazados por la entrada de inmigrantes en el contenedor conceptualizan su mecanismo de cierre, acudiendo a lexemas como colador y objeto poroso ${ }^{7}$, que lo presentan como una realidad incapaz de ponerlos a salvo de la entrada indeseada del que está fuera.

De nuevo, y como explicamos a propósito de la instanciación del contenedor en isla, se trata de imágenes adscritas a voces ajenas citadas por los autores de los textos objeto de análisis con el propósito de distanciarse de ellas, de refutarlas, porque se utilizan para defender una idea de frontera que repercute negativamente sobre el colectivo de los inmigrantes, al que se pretende cerrar el paso.

A través de estas metáforas descubriremos, por consiguiente, la ideología de los detractores del inmigrante, de quienes se manifiestan contrarios a la presencia en el país de estas personas y, por ello, utilizan imágenes que ilustran tanto lo que en su opinión debe ser una frontera, esto es, un mecanismo de cierre firme y resistente, como lo que no debería ser, es decir, 
un dispositivo por el que el inmigrante pueda acceder sin excesivos impedimentos.

Lo que venimos diciendo se manifiesta en la muestra siguiente, donde el autor se refiere a políticos republicanos que alientan la consideración de la frontera como un cierre hermético (LA FRONTERA ES UN CIERRE HERMÉTICO): el país debe ser un contenedor estanco, a salvo del peligro de la inmigración.

Según investigaciones realizadas por el Pew Hispanic Center, el flujo de inmigrantes indocumentados hacia esta nación ha registrado un marcado descenso; en marzo de 2007 había 12 millones de inmigrantes indocumentados en Estados Unidos; el año pasado había 11 millones viviendo aquí.

Los candidatos republicanos, no obstante, siguen alentando la idea de que la frontera no es segura ni hermética. Si la frontera fuera tan insegura ¿cómo explicamos que una de las ciudades más peligrosas del mundo, Juárez en México -con 3 mil asesinatos el año pasado- está pegada a una de las más seguras de Estados Unidos, El Paso? (FSD, 01-12-2011).

Con idéntico propósito de defender esta idea de frontera, las voces ajenas a las que se refieren los autores de los textos -introducidas a través de verbos dicendi (dicen, hablan) y de sintagmas nominales (los candidatos republicanos, el imaginario nortamericano o todos los republicanos) - utilizan también dominios fuente que dibujan con gran plasticidad aquello que en su opinión no debería ser. Efectivamente, si concebimos las fronteras como complejos sistemas de vigilancia dispuestos en los límites de un país para evitar la entrada de personas o sustancias no deseadas, conceptualizarlas como un objeto permeable supone violar su naturaleza esencial. Por ello, esta metáfora categoriza aquello que no debería ser una frontera, es decir, un objeto penetrable, instanciado en palabras tales como colador (LA FRONTERA ES UN COLADOR) y objeto porOso (LA FRONTERA ES UN OBJETO POROSO), que comparten una propiedad sustancial: la permeabilidad o la capacidad de ser traspasado por una sustancia en movimiento:

La amenaza crece, nos dirán. Por la frontera sur se nos pueden colar terroristas o narcotraficantes contratados por terroristas. Y como el asunto es matemáticamente posible, los que pagan las consecuencias son los inmigrantes, que no son criminales ni terroristas, y que llevan años trabajando en Estados Unidos esperando un papelito que los haga legales (FSD, 20-10-2011).

Esa es la realidad. Pero en el imaginario norteamericano -alimentado ya por la contienda por la presidencia, la crisis económica, las posiciones extremis- tas y la xenofobia- existe la percepción de que por la frontera sur de Estados Unidos se pueden colar terroristas, narcos y criminales (FSD, 20-10-2011).

Pero todos los Republicanos, incluyendo Gingrich, quieren antes una frontera segura. Todos ellos hablan de la frontera con México como si esta fuera extremadamente porosa-un lugar donde todo se vale. Lo que no dicen es que la frontera entre México y Estados Unidos está más segura que nunca. No me lo tienen que contar; yo acabo de estar ahí (FSD, 01-12-2011).

\subsection{Conceptualización metafórica del inmigrante irregular}

Como decíamos al inicio, el lenguaje figurado se utiliza igualmente en nuestro corpus para reflejar la concepción que detractores y defensores tienen del inmigrante irregular. De este modo, los autores de nuestros textos emplean la imaginería de valor axiológico negativo propia de la ideología xenófoba para distanciarse de ella y construir la propia. Estas asociaciones metafóricas procedentes del discurso contrario al inmigrante, y que Flores (2003) califica como dominant narratives, responden a la función estratégica de deslegitimar al otro, de representarlo negativamente. Como asevera Chilton (2004, p. 47):

Delegitimisation can manifest itself in acts of negative other-presentation, acts of blaming, scapegoating, marginalising, excluding, attacking the moral caracter of some individual or group, attacking the communicative cooperation of the other, attacking the rationality and sanity of the other. The extreme is to deny the humanness of the other.

Evidentemente, los textos que integran el corpus, persiguiendo la finalidad de legitimar al inmigrante, citan estas asociaciones metafóricas con el fin de refutarlas, de negarlas, porque insistentemente acuden a dominios fuente que suponen un ataque frontal contra la condición ética o moral del inmigrante o contra su humanidad.

En la primera de las analogías localizadas detectamos ya esta estrategia cuando el autor utiliza una metáfora acuñada por la ideología contraria, que demoniza (Flores, 2003) al indocumentado proyectándolo sobre el dominio fuente PERSONA DIABÓLICA (EL INMIGRANTE ES UNA PERSONA DIABÓLICA) y que se instancia en el verbo satanizar. De nuevo, a través del discurso de sus defensores, el inmigrante es percibido como el objeto de una maniobra de degradación moral, que, como veremos, se irá intensificando a través de otras metáforas que culminan en su cosificación: 
Indocumentados que muchos usan para avanzar sus agendas políticas: unos que aseguran querer ayudarlos, y otros que los satanizan (LPSD, 09-09-2011).

Como ya hemos señalado, esta proyección supone un primer avance en ese proceso de degradación al que se somete al indocumentado: por medio de un acto de agravio, se ataca la condición ética y moral de aquel a quien se culpa de las dificultades económicas y sociales que sufre el país anfitrión.

Sin embargo, el salto al vacío en esta estrategia de deslegitimar al otro surge con la identificación figurada del indocumentado con un ser inhumano. Tal metáfora se instancia en dos expresiones lingüísticas insertas con pertinacia en voces que representan el credo del antagonista del inmigrante y a las que se alude insistentemente en los textos con el deseo de rebatirlas, por cuanto entrañan, como veremos, un proceso de deshumanización implícito ${ }^{8}$ : solución humana [al problema de la inmigración irregular] y [tratar a los indocumentados] de una forma humana.

La primera de estas expresiones se enraíza en una metáfora de mayor amplitud, que proyecta la inmigración irregular sobre el dominio fuente problema (LA INMIGRACIÓN IRREGULAR ES UN PROBLEMA), según constatamos en los dos extractos siguientes:

El debate de los aspirantes republicanos de turno a la nominación presidencial republicana no arrojó nada nuevo [...]. Sus respuestas migratorias: vagas y algunas hasta ofensivas. [...].

Sólo dos de ellos dijeron que hay que buscar una solución "humana" aunque no queda claro qué significa eso (EL,16-09-2011).

Imaginé el rostro de satisfacción del "terror" de los indocumentados, Lamar Smith, el congresista republicano de Texas que preside el Comité Judicial de la Cámara Baja, si el 7 de noviembre de 2012 amanece con presidente republicano en Casa Blanca, aunque sea uno de esos que promueven soluciones "humanas" (EL, 16-09-2011).

Como vemos, del relieve gráfico aplicado en ambas muestras $^{9}$ al adjetivo humanas y denegado al sustantivo soluciones se desprende que el autor asume positivamente esa voz ajena, la suscribe (Eubanks, 2000), cuando categoriza el fenómeno de la inmigración como problema; por el contrario, observamos una asunción negativa del vocablo humana, manifestada formalmente mediante el empleo de las comillas, que, de este modo, se adscribe (Eubanks, 2000) exclusivamente a esa voz reproducida, sobre la cual ironiza. Con ello el autor manifiesta su resistencia a aceptar ese calificativo, que enmarca el debate en el escenario de la metáfora EL INMIGRANTE ES UN SER INHUMANO, frecuente entre los detractores del inmigrante irregular (Santa Ana, 2002, 2003; Musolff, 2011).

La misma utilización de la ideología de los otros observamos cuando el autor menciona voces ajenas que se refieren a la conveniencia de tratar de una forma humana, de una manera humana, a los indocumentados; a través del mismo procedimiento de relieve aplicado al vocablo humana, el autor descubre a la audiencia su deseo de rebatir el discurso ideológico de quienes suelen hacer uso de estas expresiones, por cuanto conllevan implícita la negación de la humanidad del inmigrante:

Pero ahora todo el mundo -incluyendo a los otros siete candidatos republicanos a la presidencia- está poniendo atención a la propuesta de Gingrich de tratar de una forma "humana" a los indocumentados porque él va adelante en las encuestas (FSD, 01-12-2011).

Mientras tanto, acepto la idea de tratar a todos los inmigrantes de una manera "humana". Y el primero en hacerlo ha sido Gingrich que prácticamente ya no usa el término "ilegales" para referirse a los indocumentados. Ese es un buen primer paso (FSD, 01-12-2011).

En ambas expresiones, el calificativo humana implica un razonamiento que parte de la negación tácita de la humanidad del inmigrante. Con esta metáfora negativa $^{10}$, el hablante subvierte y transgrede la Gran Cadena del Ser (Lovejoy, 1936), que se comporta aquí como una herramienta ideológica con la que los que se consideran a sí mismos humanos exhiben su capacidad de dominio. En este caso, a su arbitrio, despojan a ciertos miembros de su clase, a los inmigrantes indocumentados, de las cualidades que les corresponden por naturaleza. Como afirman Lakoff y Turner (1989, p. 213), "The Great Chain itself is a political issue. As a chain of dominance, it can become a chain of subjugation".

Sin embargo, el proceso de devaluación del indocumentado no solo lo desnuda de su humanidad sino que prosigue, negándole incluso la condición de ser vivo, al degradarlo al último nivel de la jerarquía, la de los objetos inanimados. Muestra de esta cosificación es la etiqueta de ilegal que los detractores asignan al indocumentado, quien, como cualquier otra mercancía, queda clasificado por medio de una marca, de una señal. Precisamente a este calificativo de ilegal, a este estigma, se oponen nuestros textos haciendo uso, una vez más, de ese mecanismo de relieve, las comillas, con el que expresan la negativa a aceptar como marco de conceptualización del inmigrante el cuestionamiento de su humanidad: 
Asimismo, a los latinos nos etiquetaron con la palabra peyorativa de "ilegal" e inculparon a nuestros hijos por las bajas calificaciones en las escuelas del distrito local. De acuerdo a esta gente, todo lo malo era fabricado por los latinos, mientras que lo bueno tenía ascendencia y color anglosajón (LPSD, 14-10-2011).

Cuando el gobernador de Texas y uno de los aspirantes, Rick Perry, defendió el haber promulgado un DREAM Act en Texas para permitir que los estudiantes indocumentados paguen la misma matrícula que los alumnos residentes, algunos de sus copartidarios saltaron como fieras para esgrimir sus argumentos en contra de los "ilegales" (EL, 30-09-2011).

La negación explícita de la metáfora EL INMIGRANTE ES UN SER INHUMANO y de su anclaje ideológico tiene lugar en el siguiente fragmento, en el que el autor cita, esta vez en una operación de apoyo argumentativo, una voz ajena, que, a propósito de la ley HB 56 de Alabama $^{11}$, rechaza ese proceso de deshumanización del inmigrante irregular llevado al extremo, afirmando que los seres humanos no pueden ser tratados como cosas. En este caso, aunque la proyección adopta la forma de símil ${ }^{12}$, desde una perspectiva cognitiva cabe interpretar también la negación de la correspondencia entre el inmigrante y el dominio meta de los objetos y, por ello, supone igualmente un cuestionamiento de la cosificación del indocumentado efectuada por la ideología antagonista:

Al texto de la HB 56 solo le falta reglamentar que le quiten el oxígeno a los indocumentados.

"Ganó la intolerancia. Los xenófobos republicanos [...] han de estar brincando de gusto ante la impertinente, inhumana e injusta decisión", señaló en su editorial, Ignacio Guajardo, director general de Alabama Paisano, el periódico en español más importante de ese estado, con sede en Birmingham.

\section{$[\ldots]$}

Y agregó: “¿En dónde está la sensatez, en dónde la civilidad? Los seres humanos no pueden ser tratados como cosas, en donde un día los consideran indispensables para las faenas y al otro día los consideran indeseables" (EL, 07-10-2011).

\section{CONCLUSIONES}

Hemos constatado, como era nuestro propósito, que la metáfora conceptual se comporta como una herramienta más en las operaciones de apoyo y, especialmente, de refutación argumentativas. Para ello, a partir de un corpus de artículos de opinión extraídos de la prensa estadounidense en lengua española relacionados con el fenómeno migratorio, hemos analizado las metáforas conceptuales y lingüísticas que hacen uso del esquema de imagen del recipiente para categorizar el país receptor (EL PAÍs RECEPTOR DE INMIGRANTES ES UN RECIPIENTE) y las que retratan al inmigrante irregular como un ser diabóliCO (EL INMIGRANTE IRREGULAR ES UN SER DIABÓLICO) y como un ser inhumano (EL INMIGRANTE IRREGULAR ES UN SER INHUMANO).

En lo que se refiere a la primera, los autores de los textos hacen suya una metáfora de honda raigambre en el discurso político, a la que aplican los procesos cognitivos pertinentes que les permiten transmitir su particular visión de los acontecimientos. Esta metáfora reproduce una ideología que identifica al país anfitrión con un recipiente cercado al que el inmigrante accede por su propia voluntad; este, una vez en el interior, adopta sistemáticamente el rol de agente amenazado por la expulsión del contenedor, proyectada en el dominio meta sobre la deportación. Tales correspondencias se verbalizan mediante procedimientos gramaticales diversos como la intransitividad (entrar, ingresar) y la transitividad (sacar, expulsar o expulsión), o mediante procedimientos léxico-semánticos (por la fuerza). Algunos de ellos activan en la mente del lector el esquema de imagen compulsión, reflejando la involuntariedad de la salida del contenedor.

Se constata, por consiguiente, que este ideario se opone al del discurso xenófobo, que asigna al inmigrante el rol de agente de la amenaza (Santa Ana, 2002, 2003; Flores, 2003; Cisneros, 2008; Semino, 2008; Musolff, 2011) y que categoriza al país receptor como una isla que, con sus límites, se mantiene a salvo del peligro que supone la entrada del que está fuera.

Enraizadas en este escenario, las imágenes que categorizan la frontera, proyectada sobre el cierre del contenedor, proceden de voces ajenas mencionadas por los autores de nuestros textos con el fin de refutarlas, porque descubren la ideología de los adversarios. Estas opiniones, contrarias al fenómeno de la inmigración, emplean estas imágenes para ilustrar tanto la idea de frontera que sostienen, esto es, un mecanismo de cierre hermético que impida la entrada de inmigrantes, como aquella que rechazan, es decir, un dispositivo de fácil apertura, por el que el inmigrante pueda acceder sin excesivos impedimentos (colador y piedra porosa).

Precisamente de la comparación de estos lexemas con el que emplea el discurso afín al inmigrante (puerta) para referirse al mecanismo de cierre, a la frontera, se desprende la valoración positiva que hacen del 
país anfitrión tanto los autores de los textos objeto de estudio como aquellos cuyas opiniones utilizan para apoyar sus propios argumentos, pues este vocablo, neutro fuera de contexto, en nuestro corpus se carga de una axiología positiva por contraste con los sintagmas frontera hermética, piedra porosa o colador.

El lenguaje figurado se utiliza igualmente en nuestro corpus para reflejar la concepción que detractores y defensores tienen del inmigrante irregular. De este modo, nuestros textos emplean la imaginería xenófoba de valor axiológico negativo para rechazarla, porque insistentemente acude a dominios fuente que suponen un ataque frontal contra la condición ética o moral del inmigrante o contra su humanidad.

La primera de estas analogías refutadas en los textos (EL INMIGRANTE IRREGULAR ES UNA PERSONA DIABÓLICA) refleja una maniobra de degradación moral que se intensifica en sucesivas metáforas hasta llegar a la cosificación. Esta estrategia de deslegitimar al inmigrante prosigue con su identificación figurada con un ser inhumano (EL INMIGRANTE IRREGULAR ES UN SER IN-
HUMANO). Tal metáfora se materializa en expresiones como solución "humana" y de una forma "humana", cuyo relieve gráfico indica la negativa de nuestros autores a anclar el debate en las implicaciones epistemológicas de esta analogía.

Este proceso de devaluación del inmigrante culmina con su cosificación, puesta de manifiesto mediante la etiqueta de ilegal, estigma al que se oponen los autores de estos textos haciendo uso, una vez más, del relieve gráfico para expresar su rechazo como marco de conceptualización del inmigrante el cuestionamiento de su humanidad:

Hemos comprobado, por tanto, que las metáforas analizadas y las estructuras conceptuales que generan han propiciado el diálogo virtual (Musolff, 2004) entre ideologías opuestas, defensora y detractora del fenómeno de la inmigración, y ha puesto de manifiesto que "metaphors function in dialogical argumentation" (Musolff, 2004: 146), proporcionando a los interlocutores una base conceptual para la introducción de perspectivas antagónicas sobre la cuestión debatida.

\section{NOTAS}

1 Las autoras de este artículo forman parte de la división de $\mathrm{Cog}$ nición, Textos y Contextos del Instituto Universitario de Análisis y Aplicaciones Textuales de la Universidad de Las Palmas de Gran Canaria. Este artículo se enmarca en una de sus líneas de trabajo, centrada en el estudio de la metáfora conceptual en el discurso periodístico.

2 Perelman y Olbrechts-Tyteca (1958, p. 611) describen la metáfora como el resultado de la fusión de un elemento del foro, que es el término concreto, con un elemento del tema o término abstracto y la ejemplifican acudiendo a la metáfora aristotélica tarde de la vida para explicar la vejez.

3 En este sentido, Fisher (1984), cuando habla del paradigma narrativo, dice lo siguiente:

By paradigm, I refer to a representation designed to formalize the structure of a component of experience and to direct understanding and in quiry into the nature and functions of that experience.
Fisher (1984) entiende que este paradigma narrativo sintetiza las dos vertientes de la teoría retórica: la argumentativa y la estética. Autores como Santa Ana (2002, 2003), Flores (2003) y Cisneros (2008) aplican el concepto de narrativa al debate migratorio que tiene lugar en la prensa norteamericana en lengua inglesa.

4 Chilton (1996) señala que la metáfora del contenedor también ha desempeñado un papel esencial en las relaciones internacionales. En particular la idea de seguridad se construye en términos de contención, containment, que supone la consideración de las naciones como contenedores independientes, separados, de modo que una nación debe protegerse de cualquier infiltración o invasión del exterior y las naciones amenazantes han de ser forzadas a mantenerse dentro de los límites de su propio contenedor.

5 Ruiz de Mendoza Ibáñez y Pérez Hernández (2011) descubren este mismo esquema de imagen cuando analizan la metáfora She is in deep trouble, en la que una situa- ción problemática se conceptualiza como un contenedor; las paredes del contenedor son los límites imaginarios entre la situación aludida y cualquier otro estado; la gente de dentro y fuera del contenedor se identifica con las personas afectadas o no por la situación; y, por último, la profundidad del contenedor se proyecta sobre la dificultad de encontrar una solución a la situación problemática.

6 Las iniciales que figuran tras cada uno de los fragmentos indican el medio del que han sido extraídos: EL (El Latino), FSD (Frontera San Diego) y LPSD (La Prensa de San Diego).

7 También Cisneros (2008) localiza referencias a esta porous border en la representación metafórica reflejada en los informativos de cadenas de televisión americanas tales como CNN y Fox.

8 Cisneros (2008) advierte este mismo proceso de deshumanización en las metáforas que identifican al inmigrante con sustancias amenazantes, contaminantes, peligrosas y destructivas. 
9 Como ocurre en estas y otras muestras en que se utiliza un procedimiento de relieve, el original recurre unas veces al empleo de comillas y otras, a la cursiva.

10 Santa Ana (2002, 2003) observa que en el discurso de la prensa en lengua inglesa de Los Ángeles la metáfora dominante para referirse a este colectivo es INMIGRANT AS ANIMAL. De igual modo, Musolff (2011, p. 9) observa que las metáforas que han dominado los informes sobre la inmigración estudiantil en Gran Bretaña "emphasize the economic aspect in such a way that

\section{REFERENCIAS BIBLIOGRÁFICAS}

Adam, J. M. (1986). Orientation argumentative, cohésion et progression du texte. Cahiers de Linguistique Française, 7, pp. 259-320.

Adam, J. M. (1992). Les textes: types et prototypes. Récit, description, argumentation, explication et dialogue. Paris: Nathan.

Bajtín, M. (1986). Problemas de la poética de Dostoievski. México: Fondo de Cultura Económica.

Bañón, A. M. (2002). Discurso e inmigración. Propuestas para el análisis de un debate social. Murcia: Universidad de Murcia.

Bañón, A. M. (2008). Mali y los inmigrantes malienses. Notas sobre la representación discursiva en el diario El País. En: Bañón, A. M. y Fornieles, J. (eds.). Manual sobre comunicación e inmigración. San Sebastián: Gakoa, pp. 171-200.

Charteris-Black, J. (2009). Gran Bretaña como contenedor: metáforas sobre inmigración en la campaña electoral de 2005. Discurso \& Sociedad, 3, 3, pp. 467-494.

Chilton, P. (1996). Security Metaphors: Cold War Discourse from Containment to Common House. New York: Peter Lang.

Chilton, P. (2004). Analysing Political Discourse. Theory and Practice. London and New York: Routledge.

Cisneros, J. D. (2008). Contaminated Communities: The Metaphor of "Inmigrant as Pollutant" in Media Representations of immigration. Rhetoric \& Public Affairs, 11, 4, pp. 569-601. http://dx.doi. org/10.1353/rap.0.0068 the human beings involved in the process seem to disappear".

11 La ley HB 56 del estado de Alabama, especialmente diseñada para luchar contra la inmigración ilegal, resulta especialmente controvertida en algunos de sus aspectos, como es que el Estado pueda exigir a la Policía la detención de personas sospechosas de estar en el país de manera ilegal; la obligación de las escuelas públicas de comprobar, mediante la revisión de certificados de nacimiento o declaraciones juradas, la condición de residentes legales de los estudiantes en el mo-

Douglas, M. (1984). Purity and danger: An analysis of the concepts of pollution and taboo. London: Routledge.

Eubanks, P. (2000). A War of Words in the Discourse of Trade: The Rethorical Constitution of Metaphor. Cabondale: Southern Illinois University Press.

Fairclough, N. (2003). Analysing discourse: Textual analysis for social research. London: Routledge. http://dx.doi. org/10.1177/0957926503014001927

Fisher, W. R. (1984). Narration as human communication paradigm: the case of public moral argument. Communication Monographs, 51, pp. 1-22. http://dx.doi. org/10.1080/03637758409390180

Flores, L. A. (2003). Constructing Rhetorical Borders: Peons, Illegal Aliens, and Competing Narratives of Inmigration. Critical Studies in Media Communication, 20, 4, pp. 362-387. http://dx.doi. org/10.1080/0739318032000142025

Hamilton, C. A. (2003). Genetic roulette: On the cognitive rethoric of biorisk. En: Dirven, R. Frank, R. y Pütz, M. (eds.). Cognitive Models in Language and thought. Ideology, Metaphors and Meanings. Berlin, New York: Mouton de Gruyter, pp. 353-393.

Johnson, M. (1987). The body in the mind: The bodily basis of meaning, imagination, and reason. Chicago: University of Chicago Press.

Johnson, M. (1993). Moral imagination: Implication of cognitive science for ethics. Chicago: University of Chicago Press. mento de la inscripción; o poner en duda la legalidad de los contratos de trabajo de personas que carecen de permiso de residencia.

12 Como señalan Lakoff y Turner (1989, p. 133) a propósito de la distinción tradicionalmente establecida entre metáfora y símil, “[...] in both cases, one concept is being understood in terms of another. On the whole, the syntactic form of an utterance has little, if anything, to do with whether metaphor is involved in comprehending it".

Kövecses, Z. (2002). Metaphor: A practical introduction. Oxford: Oxford University Press. http://dx.doi.org/10.1017/ CB09780511614408

Kövecses, Z. (2005). Metaphor in Culture. Universality and Variation. Cambridge: Cambridge University Press.

Lakoff, G. (1989). Some empirical results about the nature of concepts. Mind and Language, 4, 1-2, pp. 103-129. http:// dx.doi.org/10.1111/j.1468-0017.1989. tb00244.x

Lakoff, G. (2008). The Political Mind. Why You Can't Understand 21st-Century Politics with an 18th-Century Brain. New York: Penguin.

Lakoff, G. y Johnson, M. (1980). Metaphors We Live By. Chicago and London: University of Chicago Press.

Lakoff, G. y Johnson, M. (1999). Philosophy in the flesh: The embodied mind and its challenge to Western thought. New York: Basic Books.

Lakoff, G. y Turner, M. (1989). More than Cool Reason. Field Guide to Poetic Metaphor. Chicago and London: University of Chicago Press. http://dx.doi.org/10.7208/ chicago/9780226470986.001.0001

Le Guern (1973). Sémantique de la métaphore et de la métonymie. Paris: Larousse.

Lovejoy, A. O. (1936). The Great Chain Of Being: A Study of the History of an Idea. Cambridge, Mass.: Harvard University Press. 
Mandler, J. M. (1992). How to build baby: II. Conceptual Primitives. Psychological Review, 99, 4, pp. 587-604. http://dx.doi.org/10.1037/0033295X.99.4.587

Millán, J. A. y Narotzky, S. (1986). Introducción a la traducción española de $\mathrm{G}$. Lakoff y M. Johnson, Metáforas de la vida cotidiana. Madrid: Cátedra.

Musolff, A. (2004). Metaphor and Political discourse. Analogical Reasoning in Debates about Europe. Great Britain: Palgrave Macmillan. http://dx.doi. org/10.1057/9780230504516

Musolff, A. (2011). Migration, media and deliberate metaphors. Metaphorik.de, 21, pp. 7-19.

Osborn, M. (1967). Archetypal Metaphor in Rethoric: The Light-Dark Family. Quarterly Journal of Speech, 53, 2, pp. 115-126. http://dx.doi. org/10.1080/00335636709382823

Osborn, M. y Ehninger, D. (1962). The Metaphor in Public Address. Speech Monograph, 29, pp. 223-234. http://dx.doi. org/10.1080/03637756209375346

Peña Cervel, S. (1999). Subsidiarity relationships between image-schema: an approach to the force schema. Journal of English Studies, 1, pp. 187-207.

Peña Cervel, S. (2012). Los esquemas de imagen. En: Ibarretxe Antuñano, I. y Valenzuela, J. (dirs.)., Lingüística cognitiva. Barcelona: Anthropos, pp. 69-96.

Perelman, Ch. y Olbrechts-Tyteca, L. (1958). Traité de L'Argumentation. La nouvelle Rhetorique. Paris: Presses Universitaires de France.

Pielenz, M. (1993). Argumentation und Metapher. Tübingen: Gunter Narr Verlag.

Real Academia Española. (2001). Diccionario de la Lengua Española. Madrid: Espasa-Calpe.

Ruiz de Mendoza Ibáñez, F. J. y Otal, J. L. (2002). Metonymy, grammar and communication. Granada: Comares.

Ruiz de Mendoza Ibáñez, F. J. y Pérez Hernández, L. (2011). The contemporary theory of metaphor: myths, developments and challenges. Metaphor and Symbol, 26, 3, pp. 161-185. http://dx.doi.org/10.1080/ 10926488.2011.583189

Santa Ana, O. (2002). Brown Tide Rising. Metaphors of Latinos in Contemporary American Public Discourse. Austin: University of Texas Press.
Santa Ana, O. (2003). Three mandates for anti-minority policy expressed in U.S. public discourse metaphors. En: Dirven, R. F., R. y Pütz, M. (eds.). Cognitive Models in Language and Thought. Ideology, Metaphors and Meanings. Berlin, New York: Mouton de Gruyter, pp. 199-227.

Santibáñez, C. (2010). Metaphors and Argumentation: The case of Chilean parliamentarian media participation. Journal of Pragmatics, 42, pp. 973989. http://dx.doi.org/10.1016/j.pragma.2009.08.019

Semino, E. (2008.). Metaphor in Discourse. Cambridge: Cambridge University Press.

Sweetser, E. (1990). From etimology to pragmatics: Metaphorical and cultural aspects of semantic structure. Cambridge: Cambridge University Press. http://dx.doi.org/10.1017/ CBO9780511620904

Toulmin, S. (1958). The uses of argument. Cambridge: Cambridge University Press.

Turner, M. (1991). Reading minds: The study of English in the age of cognitive science. Princeton, NJ: Princeton University Press. 